\title{
THE COMBINED DIAGNOSTIC PROCEDURE OF BRONCHOGRAPHY AND BRONCHOSCOPY
}

\author{
BY
}

\author{
S. KALINOWSKI AND T. W. LLOYD \\ From St. Wulstan's Hospital, Malvern
}

(RECEIVEd For PUblication AUgust 31, 1955)

The application of bronchography to pulmonary tuberculosis has been limited until recently by the fear of prolonged alteration of the radiograph by retained opaque medium in the alveoli. In 1945 Dormer, Friedlander, and Wiles first described the use of a mixture of sulphanilamide and iodized oil, and this was used later by Houghton and Ramsay (1951). Though this mixture largely avoided the difficulty of retention in the alveoli, it was extremely viscous and rather difficult to expel from the syringe. The introduction of propyliodone ("dionosil") has rendered the use of such mixtures unnecessary, since any propyliodone which does reach the alveoli is absorbed very quickly, leaving no radiological opacity.

Propyliodone is available in both oily and aqueous suspension. There have been reports that the aqueous preparation is irritant and provokes cough. This has not been frequent in our experience, and for some time we have used aqueous "dionosil" in preference to oily preparations, to which there is at least the theoretical objection that their use may lead to lipoid-granulomatous changes in the lung (Felton, 1953). Moreover, the aqueous preparation allows ample time to the operator. It is possible to take 15 to 20 minutes in posturing and transporting the patient without fear of troublesome alveolar filling, especially if the medium is at a low temperature at the time of injection.

The object of this paper is to present the results of combining bronchography with bronchoscopy in 100 consecutive cases. It is a routine in this, as in most centres, to perform bronchoscopy before lung resection, and the general interest that has developed in tracheo-bronchial tuberculosis in the last 10 years has led to much more frequent bronchoscopy in the medical management of pulmonary tuberculosis. We have taken the opportunity of bronchoscopy to carry out simultaneous bronchography wherever it seemed indicated during the past year. The objectives were in most cases the localization of segmental disease and the diagnosis of bronchiectasis or bronchial stenosis.

The patients for the most part were in-patients with pulmonary tuberculosis. A few were outpatients attending for diagnosis of a variety of conditions.

\section{TECHNIQUE}

After the whole procedure has been explained to the patient, he receives omnopon and scopolamine as premedication. Butacaine sulphate $2 \%$ is used for local anaesthetic to pharynx, larynx, and trachea. After bronchoscopy has been completed the bronchoscope is withdrawn until the tip lies about $\frac{1}{2}$ in. $(1.3 \mathrm{~cm}$.) below the carina. The main bronchus thus exposed is sprayed with the anaesthetic solution through a Clerf's spray and the excess, if any, is removed by suction. Twenty millilitres of the opaque medium is injected slowly through a Negus suction tube with gum elastic tip, the suction tube having been adapted to fit a Martin's syringe. After removal of the suction tube and bronchoscope the patient is postured on the table to ensure filling of all bronchi before being transferred, in the lateral position, by trolley to the $x$-ray department. Films are taken in the erect position.

\section{RESUlts}

We have jointly reviewed the films obtained and found wholly satisfactory readable pictures in 92 of 100 cases, our criterion being that all branches are clearly shown well beyond the first subsegmental division.

Of the remainder: (a) In three cases the only segmental bronchus not filled was one serving a part of the lung grossly affected by tuberculosis. Uncertainty as to the cause, whether stenosis, mucous obstruction, or inadequate technique, led us to classify these as being of doubtful value. (b) In one case of rather gross bronchiectasis the cough reflex was not sufficiently suppressed; a 
poor picture resulted. (c) In one there was good filling of all segmental branches as far as, but not beyond, the first subsegmental division, presumably due to failure to posture effectively. (d) In three cases there was alveolar filling sufficient to obscure a part of the bronchial tree. One of these was our first patient ; in this case the medium was warmed before injection and rather extreme alveolar filling of a lower lobe occurred. This was followed by apparent spread of disease to this lobe which resolved slowly, and this was the only complication of any kind that we have experienced. Since this first case we have invariably stored propyliodone in the refrigerator until required.

\section{CONClusion and Summary}

The combination of bronchography with bronchoscopy has been reported by others using other media (Lecutier, 1954). Propyliodone (aque- $\ddot{\Rightarrow}$ ous) has also been described as a satisfactory medium in pulmonary tuberculosis by Elphinstone, Iles, and Laidlaw (1954). We can confirm that the method is simple and effective, and are well satisfied with this medium. Where both bronchoscopy and bronchography are indicated it is a con- ळ venience to the physician as well as a kindness to the patient to combine them.

\section{REFERENCES}

Dormer, B. A., Friedlander, J., and Wiles, F. J. (1945).

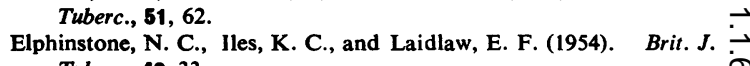
Tuberc., 48, 33.

Felton, W. L. (1953). J. thorac. Surg., 25, 530.

Houghton, H. G. H., and Ramsay, J. H. Rolland (1951). Brit. J. 옥 Tuberc., 45, 182.

Lecutier, E. R. (1954). Ibid.. 48, 184. 